\title{
Formation Damage Induced by Water-Based Alumina Nanofluids during Enhanced Oil Recovery: Influence of Postflush Salinity
}

\author{
Ichhuy Ngo,* Kyuro Sasaki, Ronald Nguele, and Yuichi Sugai
}

Cite This: ACS Omega 2020, 5, 27103-27112

Read Online

ABSTRACT: Injecting nanofluids (NFs) has been proven to be a potential method to enhance oil recovery. Stranded oil is produced by wettability alteration where nanoparticles form a wedge film on pore wall surfaces, which is thought to shrink the pore space of the reservoir. Furthermore, ensuring the stability of the injected NF during the application is a major challenge. A low permeability reservoir and salinity of water make the response of NF injection to the formation damage more difficult. This article, therefore, studied the formation damage induced by the injection of alumina nanofluids (Al-NFs) in a relatively

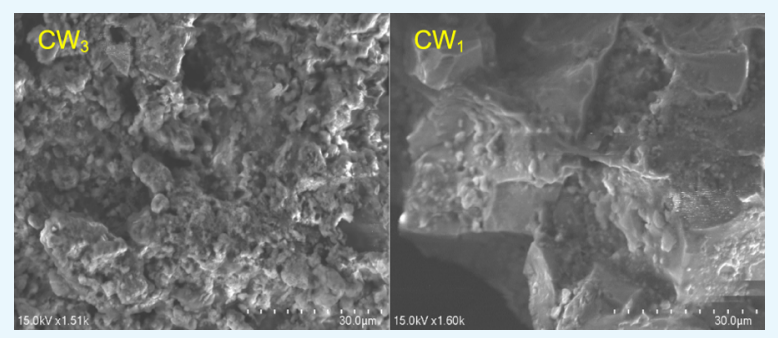
low permeability $(7.1 \mathrm{mD})$ sandstone core. The salinity of the postflush water was also considered to mitigate the destructive impact. Al-NF was formulated by dispersing alumina nanoparticles (Al-NPs) in an aqueous solution of sodium dodecylbenzene sulfonate (SDBS) at its critical micelle concentration (CMC, 0.1 wt \%). The formation damage, inherent to Al-NF injection, was evaluated by core-flooding tests. The assays consisted of the injection of $1 \mathrm{PV}$ Al-NF $(0.05 \mathrm{wt} \%)$ at the trail of which postflush at different salinities was flooded. The study found that the salinity of the postflush has an effect on the formation damage and oil recovery factor (RF). A chase water with a salinity concentration of 3 wt \% sodium chloride $(\mathrm{NaCl})$ produced an $\mathrm{RF}$ of $8.7 \%$ compared to a base case of water-flooding with a pressure drop of up to $13 \mathrm{MPa}$ across the core (70 mm in length). These results pertained to the deposition of Al-NPs at the injection end. However, lowering the postflush salinity to $1 \mathrm{wt} \% \mathrm{NaCl}$ mitigated the formation damage as evidenced by the decrease in pressure (35\%) and an increase in $\mathrm{RF}$ to $17.2 \%$.

\section{INTRODUCTION}

At present, conventional crude oil resources have entered the mature phase, leading to a more challenging production method. The next step of oil production will be provided through more advanced enhanced oil recovery (EOR) approaches and from the unconventional oil resources. Therefore, a low-permeability reservoir is one of the future alternatives to unconventional resources. A low-permeability reservoir is difficult to develop due to the low porosity, permeability, and narrow pore throat structure. These features result in the flow restriction of reservoir fluids and hence a lower ultimate oil recovery. ${ }^{1,2}$

Therefore, the development of a production method to interact directly with the in situ oil in tight porous media is an option to enhance oil recovery of a low-permeability reservoir. Nanofluids (NFs) thereby become a potential candidate due to the constituent nanoparticles (NPs) that possess an average size of below $100 \mathrm{~nm}$. Extensive research studies have covered the potential of NPs in various applications such as chemical solutions $^{3-5}$ and heat transfer agents. ${ }^{6-9}$ The primary mechanisms pertaining to oil production using NPs include lowering the interfacial tension (IFT) between the injected aqueous nanofluids and in situ oil and the alteration of the wettability of the rock surface to water-wet conditions. ${ }^{10-13}$
Joonaki and Ghanaatian ${ }^{14}$ investigated the effect of the injecting schedules of an alumina nanofluid (Al-NF) on ultimate oil recovery. The optimum recovery reached $92.5 \%$ by the injection of the alumina nanofluid without the preflush of brine. Giraldo et al. ${ }^{4}$ found that a strong oil-wet sandstone could be altered to a water-wet one using Al-NF. An experimental study by Kiani et al. ${ }^{15}$ showed that up to $71.48 \%$ of oil is recovered using $\gamma$-Al-NF. They found that more oil is produced at higher adsorption of Al-NPs by increasing the salt load within theNF.

The adsorption of Al-NPs supports the wettability alteration to be more water-wet, and Giraldo et al. ${ }^{4}$ and later Hosseini et al. ${ }^{16}$ showed that the increase in oil mobilization is owing to IFT reduction and wettability alteration. $\mathrm{Li}$ and Torsaeter ${ }^{17}$ argued that wettability alteration is achieved by the adsorption of NPs on the rock surface, observations thatwere confirmed by Sagala et al. ${ }^{18} \mathrm{NPs}$ are adsorbed onto the pore surface

Received: May 26, 2020

Accepted: September 30, 2020

Published: October 17, 2020 
Table 1. Synthetic Formation and Injected Water Composition (in wt \%) ${ }^{a}$

\begin{tabular}{|c|c|c|c|c|c|c|c|c|c|}
\hline ionic composition & $\mathrm{Na}^{+}$ & $\mathrm{Ca}^{2+}$ & $\mathrm{Mg}^{2+}$ & $\mathrm{K}^{+}$ & $\mathrm{Cl}^{-}$ & $\mathrm{SO}_{4}{ }^{2-}$ & $\mathrm{HCO}_{3}^{-}$ & TDS & $\mathrm{pH}$ \\
\hline $\mathrm{FB}$ & 0.94 & 0.09 & 0.03 & 0.03 & 1.61 & 0.28 & 0.01 & 3.00 & 5.1 \\
\hline DI water & & & & & & & & 0 & 6.8 \\
\hline $\mathrm{CW}_{1}$ & 0.39 & & & & 0.61 & & & 1.00 & 5.3 \\
\hline $\mathrm{CW}_{3}$ & 1.18 & & & & 1.82 & & & 3.00 & 5.1 \\
\hline $\mathrm{CW}_{5}$ & 1.97 & & & & 3.03 & & & 5.00 & 5.0 \\
\hline
\end{tabular}

during injection of NF into oil-wet sandstones, resulting in pore walls' wettability alteration.

Despite the promising results of NFs in EOR, NP adsorption onto the rock surface and pore throats results in permeability impairment under certain conditions. ${ }^{19}$ This phenomenon has been less regarded presumably because the wealth of literature covering NF-EOR is directed toward higher permeability formations in which adsorption does not have a significant impact on production. Regarding the characteristics of the lowpermeability reservoir, the stability effect of NFs is sensitive and must be monitored throughout the application. Salinity of water is one of the major concerns in NF-EOR and it significantly impacts the NF stability. To the best of our knowledge, there are very limited investigations about the effects of NP adsorption within the low-permeability core and the associated formation damage in consideration of the postflush salinity.

Therefore, this work aims at evaluating the formation damage subsequent to the injection of water-based Al-NFs, formulated by dispersing Al-NPs in an aqueous solution of sodium dodecylbenzene sulfonate (SDBS) following a procedure discussed elsewhere. ${ }^{20,21}$ The effects of salinity gradient on both interfacial tension (IFT) and wettability are studied. The formation damage is evaluated by core-flooding assays by Al-NFs in water-flooded Berea sandstone at the trail of which chase water or postflush at different salinities was injected. The chemistry of the effluent water was analyzed to understand the inherent formation damage mechanisms.

\section{EXPERIMENTAL SECTION}

2.1. Materials. Lyophilized Al-NPs were purchased from Tecnan (99.9\% pure, with a white appearance and the particle size ranged from 10 to $20 \mathrm{~nm}$ ). The average specific surface area of $\mathrm{Al}-\mathrm{NPs}$ is $123.5 \mathrm{~m}^{2} / \mathrm{g}$. Al-NPs are the proven nanoparticles in the application of EOR. ${ }^{22}$ The aluminum (Al) within them provides a clear response in the Berea sandstone where $\mathrm{Al}$ is the minor element to evaluate the pore blockage (formation damage).

Sodium dodecylbenzene sulfonate (SDBS), an anionic surfactant, was utilized to prepare the base fluid (purchased from Sigma-Aldrich, $99.9 \%$ pure, and possesses a molecular weight of $342.4 \mathrm{~g} / \mathrm{mol}$ ). Anionic surfactant possesses a negatively charged polar head that reduces the adsorption onto the Berea sandstone surface. ${ }^{23,24}$

A dead oil, sampled from a Japanese oil field, was used as the candidate oil. The density and absolute viscosity of dead oil were measured at the target formation temperature $\left(45^{\circ} \mathrm{C}\right)$ to be $867.6 \mathrm{~kg} / \mathrm{m}^{3}$ and $5.67 \mathrm{mPa} \cdot \mathrm{s}$, respectively. The oil has a total acid number (TAN) of $1.86 \mathrm{mg}$ of potassium hydroxide per gram of oil $(\mathrm{mg} \mathrm{KOH} / \mathrm{g}$ oil), which was determined following the ASTM D974-11 standard.

A low-permeability Berea sandstone core $(6.9-7.4 \mathrm{mD})$ was used for core-flooding tests. The core is $45.5 \mathrm{~mm}$ in diameter and $72.1 \mathrm{~mm}$ in length. Due to the smaller pore diameter, Al$\mathrm{NP}$ adsorption through wettability alteration is required to evaluate the negative impact on the formation damage during EOR application.

2.2. Methods. 2.2.1. Preparation of Base Fluid, Nanofluid, and Formation Brine. The surfactant solution was prepared by dissolving $0.1 \mathrm{~g}$ of SDBS in $100 \mathrm{~mL}$ of deionized (DI) water. SDBS solution at $0.1 \mathrm{wt} \%$ was found to be thecritical micelle concentration (CMC), and it was utilized as the base fluid to formulate nanofluids. At lower and higher concentrations, the NFs were unstable, gaining no further advantages over the CMC.

Aqueous NFs were prepared by adding $0.05 \mathrm{~g}$ of Al-NPs into $100 \mathrm{~mL}$ of base fluid following a two-step approach using carbon dioxide $\left(\mathrm{CO}_{2}\right)$ bubbling. A greater amount of Al-NPs have been tested to cause instability of formulated NFs, which is inappropriate to implement in later tests. The mixture was first stirred by a magnetic stirrer at $1500 \mathrm{rpm}$ for $30 \mathrm{~min}$. Then, it was sonicated in an ultrasonic bath (model MCD-3) at a frequency of $40 \mathrm{kHz}$ for $30 \mathrm{~min}$ where $\mathrm{CO}_{2}$ was allowed to bubble during the sonication. The stirring and sonication durations were verified to be adequate to produce stable $\mathrm{Al}$ NFs from the trails ranging from 10 to $60 \mathrm{~min} . \mathrm{CO}_{2}$ gas was bubbled into the mixture to improve the stability of the nanofluid by the enhancement of the cavitation collapse, which proved to be good to obtain a more stable nanofluid. ${ }^{21}$

The formation brine (FB) has a salinity of approximately 3 wt $\%$ and was synthesized in-house primarily from sodium chloride $(\mathrm{NaCl})$, calcium chloride $\left(\mathrm{CaCl}_{2}\right)$, magnesium chloride $\left(\mathrm{MgCl}_{2}\right)$, potassium chloride $(\mathrm{KCl})$, sodium sulfate $\left(\mathrm{Na}_{2} \mathrm{SO}_{4}\right)$, and sodium bicarbonate $\left(\mathrm{NaHCO}_{3}\right)$. The chemicals were obtained from Junsei Chemical (Tokyo, Japan) and were used as received.

Given the interest of this study is the influence of salinity (wt $\% \mathrm{NaCl}$ ), the postflush was modeled with the consideration of only salinity. The choices of salinity (DI, $\mathrm{CW}_{1}, \mathrm{CW}_{3}$, and $\mathrm{CW}_{5}$ ) are based on the stability test of Al-NFs. $\mathrm{CW}_{5}$ was chosen to confirm the assumption that high salinity makes AlNFs unstable during core-flooding, and less saline cases were considered to investigate the formation damage provided by stable Al-NFs. The chemical compositions are shown in Table 1.

2.2.2. Interfacial Tension and Contact Angle Measurements. A DropMaster (model DMS-401), using a pendent drop method, was used to evaluate both IFT and wettability. The latter was represented by the contact angle. Equipped with a high-resolution camera, the shape of the droplet was captured and analyzed using the Young-Laplace equation. Prior to the contact angle measurement, a segment of the Berea sandstone was cut into $1.5 \mathrm{~cm}$ in length, $1 \mathrm{~cm}$ in width, and $0.2 \mathrm{~cm}$ in thickness and polished to possess a smooth surface. The dimension of the segment was developed to fit the container glass of the DropMaster. 
The polished rock segment was then saturated in the dead oil sample and aged for 7 days at a temperature of $85{ }^{\circ} \mathrm{C}$ to ensure a complete an oil-wet surface. Then, the oil-saturated rock segment was immersed in Al-NF for $12 \mathrm{~h}$ at a defined salinity as there were no significant changes in the results at longer contact. An oil drop was then deposited beneath the rock segment, and a photo of the drop was recorded by a highresolution camera to measure the contact angle. The implementation of the contact angle method is well fitted with the nanofluid environment where microscopic changes upon wettability alteration can be measured precisely.

2.2.3. Core-Flooding Test. Core-flood assays were conducted in an apparatus schematized in Figure 1 to obtain the oil recovery factor (RF) and rock-fluid and fluid-fluid chemical interactions during fluid injection and for formation damage inspection after injection.

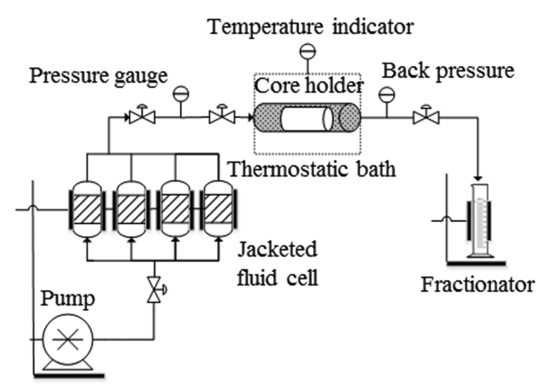

Figure 1. Schematic representation of the core-flooding apparatus.

The setup includes a high-precision syringe pump, jacketed cells containing injection fluids, injector pressure indicator, thermostatic bath, temperature indicator, Hassle core holder, back pressure regulator, and fractionators. Core-flooding was performed at the reservoir temperature of $45^{\circ} \mathrm{C}$.

The core was then dried in an oven at $110^{\circ} \mathrm{C}$ for $12 \mathrm{~h}$. The dried samples are weighed and saturated with FB. The porosity of the core varies from 11 to $14 \%$ and absolute permeability varies from 6.9 to $7.4 \mathrm{mD}$, following Darcy's law. Then, the dead oil sample is injected into core samples until irreducible water saturation was obtained. To restore the oil-wet condition, the oil-saturated cores were aged for 2 weeks.

Conventional water-flooding was performed by flooding the aged sandstone with FB for 3 pore volume (PV) for no or less than $0.1 \%$ of oil cut observed in further injection in all cases in this study. The oil recovery factor (RF) was computed as the fraction of the oil production per PV. When the oil cut was less than $0.1 \%$, Al-NF was injected for $1 \mathrm{PV}$ to ensure the full contact of the Al-NF with the trapped oil and pore surfaces, so as to evaluate its effectiveness in terms of additional oil production. In the postflush, CW was injected to investigate its effects on Al-NP deposition. All experiments were repeated for at least three runs to ensure the accuracy of the results.

At the end of the core-flooding tests, the morphology of the core surfaces, at both injector and producer, was monitored by scanning electron microscopy (SEM, model SU3500, Hitachi High-Technologies) and energy-dispersive X-ray spectroscopy (EDX) to study the formation damage represented by pore blockage and the elemental composition of the blocking agents.

2.2.4. Chemistry of the Effluent Water. The effluent of the core-flood experiments was analyzed. The concentration of AlNPs was determined following the Beer-Lambert principle using a UV-visible spectrophotometer (model 2450, Shimad$\mathrm{zu})$. The spectrophotometer reagent solution was prepared by dissolving $0.1 \mathrm{~g}$ of 1-(-2pyridylazo)-2-naphthol (PAN) in 100 $\mathrm{mL}$ of DI water. The detailed procedures regarding the ratio of reagent to effluent and the development of calibration line are given in Figure S1, Supporting Information.

\section{RESULTS AND DISCUSSION}

3.1. Influence of Salinity on IFT and Wettability. 3.1.1. Influence on IFT. In a preliminary analysis, $\mathrm{NaCl}$ at a concentration of $0.5,1,2,3,4$, and 5 wt \% was added into AlNF to investigate its stability (Figure 2).

At a constant temperature of $45{ }^{\circ} \mathrm{C}$ (reservoir condition), the formulated Al-NF was stable at up to $3 \mathrm{wt} \% \mathrm{NaCl}$ (Figure $2 \mathrm{a})$. Upon increasing the salinity to 4 and 5 wt $\% \mathrm{NaCl}$, the $\mathrm{Al}$ -

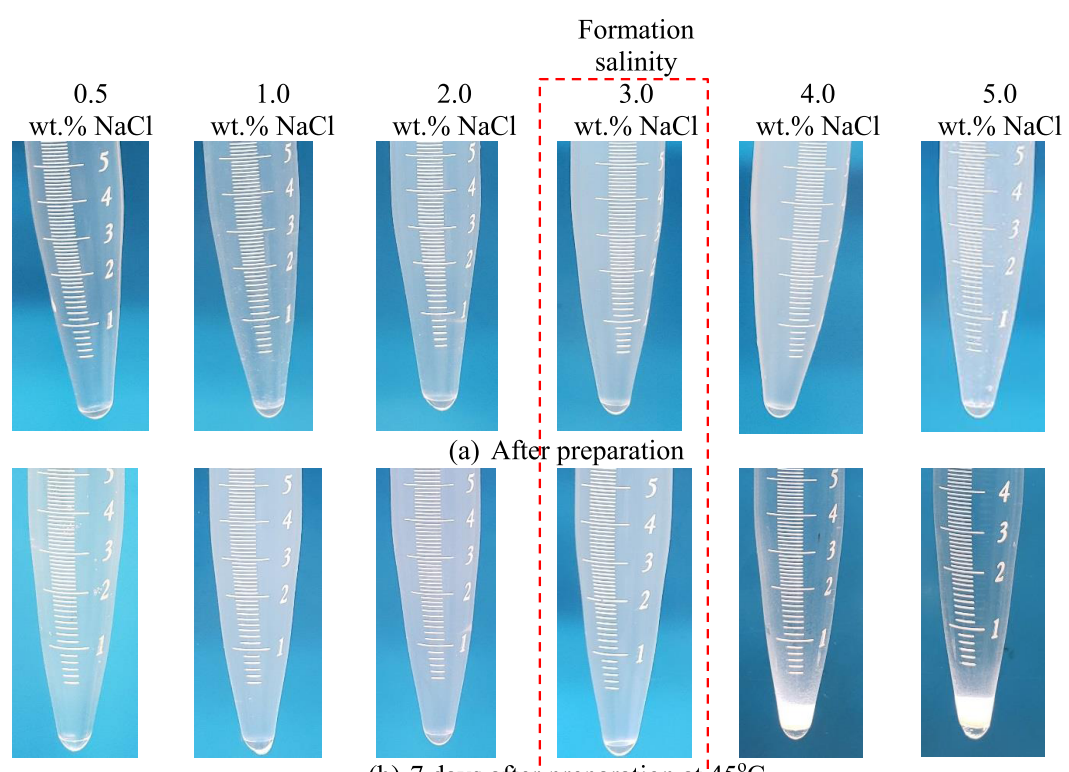

(b) 7 days aften preparation at $45^{\circ} \mathrm{C}$

Figure 2. Effect of $\mathrm{NaCl}$ concentration on $\mathrm{Al}-\mathrm{NF}$ stability (a) after preparation and (b) 7 days after preparation at $45{ }^{\circ} \mathrm{C}$. 
NPs within Al-NF formed aggregates and later deposited due to its high-density contrast to the base fluid (Figure $2 b$ ). In this sense, a lower concentration of $\mathrm{NaCl}(<0.5 \mathrm{wt} \%)$ is of less interest to study its effects on Al-NF stability.

Owing to the repulsive force developed by the SDBS monomers, the Al-NP is stably dispersed within Al-NF when the electrolyte $\left(\mathrm{Na}^{+}, \mathrm{Cl}^{-}\right)$is at a lower concentration (herein, $\mathrm{NaCl}$ ) than that disturbs its electrostatic stability, and above this concentration, for instance 4 wt $\% \mathrm{NaCl}$, the repulsive potential of the electrical double layer is reduced, ${ }^{25}$ indicated by the formation of an aggregate (Figure $2 \mathrm{~b}$ ).

At high concentrations of salt (4 and 5 wt $\% \mathrm{NaCl}$ ), $\mathrm{Na}^{+}$ ions compete with Al-NPs to adsorb on the SDBS monomer. In this sense, the number of unattached Al-NPs increases and they collide with other free Al-NPs. The Al-NF becomes unstable when the attractive force is larger than the repulsive force, as suggested by the Derjaguin, Verway, Landau and Overbeek (DVLO) theory. ${ }^{26,27}$ Due to the attractive force, many Al-NPs join together to form aggregates, which increases their density. Because of their greater density, the aggregates then fail to form a suspension in the base fluid and are deposited.

Looking at the effect of $\mathrm{NaCl}$ concentration on IFT (Figure 3), it was found that IFT responded differently to the increasing $\mathrm{NaCl}$ gradient.

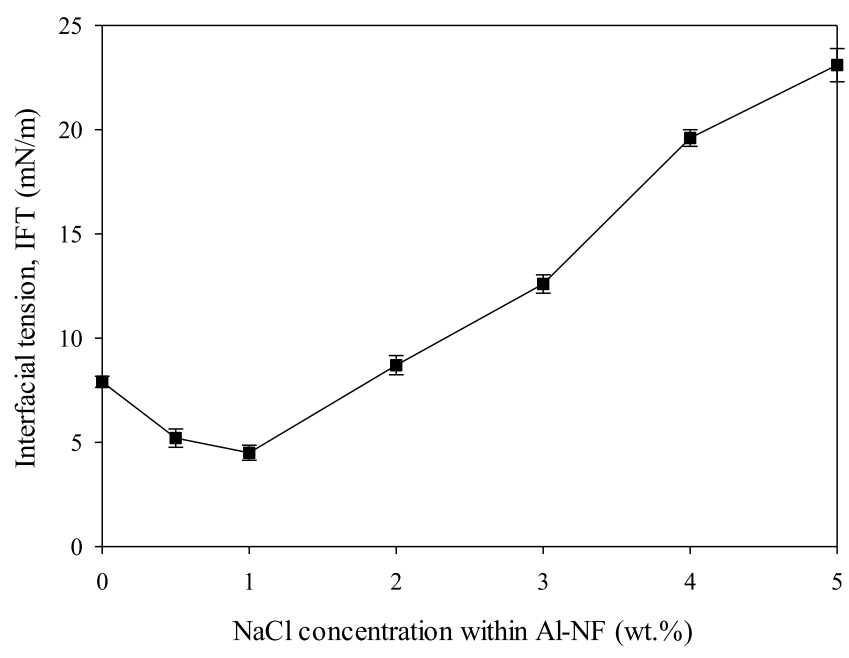

Figure 3. Effects of the $\mathrm{NaCl}$ concentration on IFT.

The IFT of the original Al-NF $(0 \mathrm{wt} \% \mathrm{NaCl})$ is $7.9 \mathrm{mN} / \mathrm{m}$. IFT decreases to $5.2 \mathrm{mN} / \mathrm{m}$ at $0.5 \mathrm{wt} \% \mathrm{NaCl}$ and reaches the lowest of $4.5 \mathrm{mN} / \mathrm{m}$ at 1 wt $\% \mathrm{NaCl}$. Upon increasing $\mathrm{NaCl}$ above 2 wt \%, IFT increases back to $8.7 \mathrm{mN} / \mathrm{m}$ and reaches $23.1 \mathrm{mN} / \mathrm{m}$ at 5 wt $\% \mathrm{NaCl}$. Given that $\mathrm{Al}-\mathrm{NF}$ is prepared from the surfactant base fluid, adding salts to the system leads to alter the surfactant monomer distribution at the oil and aqueous interface and results in IFT value changes. ${ }^{28}$

At $\mathrm{NaCl}$ concentration below $1 \mathrm{wt} \%$, the activity coefficient $a_{i}$ of the salt increases, in which its molecules transfer to the oil phase. The presence of salt at the interface, which makes the surface excess concentration $\Gamma_{i}$ positive, consequently lowers the IFT according to the Gibbs adsorption isotherm. However, for the higher $\mathrm{NaCl}$ concentration, herein from 2 to $5 \mathrm{wt} \%$ $\mathrm{NaCl}$, an increase in IFT is related to the dominant mechanism of the salting-out effect. ${ }^{29}$ The $\mathrm{NaCl}$ electrolyte occupies most of the space in the solution, which thereby reduces the solubility and stability of SDBS. Hence, SDBS monomers are eliminated from the solution, which leads to the increase in IFT.

Surfactant monomers at the interface are depleted and transferred back to the oil phase and break the balance of oilwater interface adsorption.

3.1.2. Influence on Wettability. The contact angle of the oil droplet formed between the aged oil-wet rock and Al-NF was used to evaluate the wettability alteration. The results are shown in Figure 4.

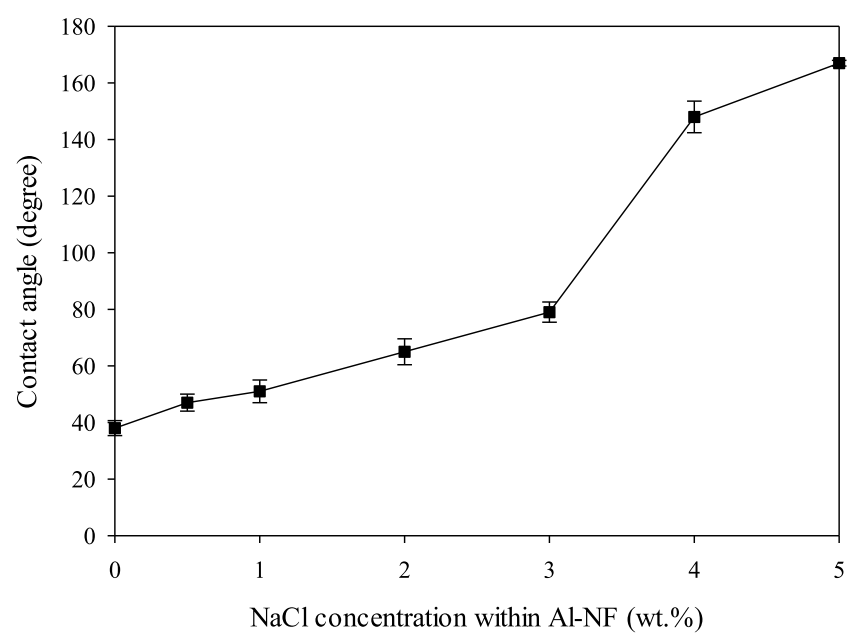

Figure 4. Effects of $\mathrm{NaCl}$ on the contact angle between the sample oil droplet and rock segment.

At $\mathrm{NaCl}$ concentrations from 0 to $3 \mathrm{wt} \%$, the contact angle of the oil droplet remains between 35 and $79^{\circ}$, indicating the water-wet rock surface as per the literature. ${ }^{30,31}$ A smaller angle formed between the oil droplet and surface indicates the lower adherence of oil to the rock surface. In other words, the oil liberation in the mentioned environment is promising compared to the larger contact angle where a larger angle of the oil droplet makes it attach to the rock surface. This is owing to the interactions of nanoparticles with asphaltene of crude oil, surface-active components of the oil droplet, that transfer nanoparticles toward the rock-oil and nanofluid-oil interfaces. $^{28}$

However, at higher salinity (above 4 wt $\% \mathrm{NaCl}$ ), the contact angle increases to $148^{\circ}$ and further increases to $166^{\circ}$ at 5 wt $\% \mathrm{NaCl}$. This behavior is seemingly attributed to heteroaggregation at high salinity as observed in Figure 2. The agglomeration of Al-NP and further the precipitation due to the density difference within the base fluid. This leads to a lack of interactions at the rock-oil and nanofluid-oil interfaces and fails to alter the rock surface to a water-wet one. A similar observation was reported by Wasan and Nikolov ${ }^{32}$ and Dai et al. $^{33}$

They argued that the wettability of the rock surface is altered through a structural disjoining pressure developed by a wedgelike film of nanoparticles at the rock-oil interface. As a result, deposited nanoparticles are unable to achieve wettability alteration.

3.2. Evaluation of Oil Recovery Increment and Formation Damage by Al-NF. 3.2.1. Increment in Oil Production. Figure 5 shows the results of the RF obtained from Al-NF and injections. 


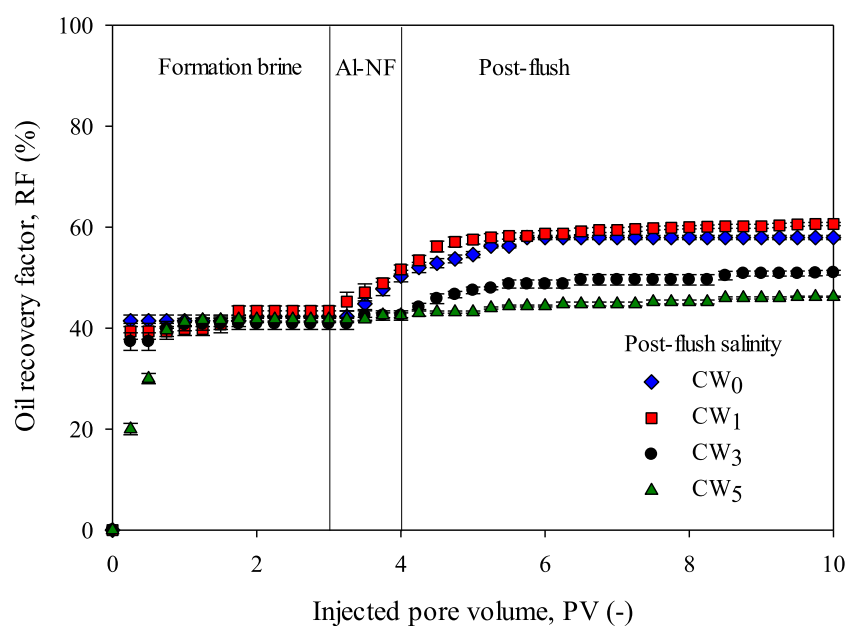

Figure 5. Influence of chase water salinity on the oil recovery factor.

After the injection of $\mathrm{FB}$, from 0 to $3 \mathrm{PV}$, RF was $42 \%$ on average. The injection was then shifted to Al-NF for $1 \mathrm{PV}$ (from 3 to $4 \mathrm{PV}$ ) when the oil cut was less than $0.1 \%$. An increase in RF was observed after $0.5 \mathrm{PV}$ of the injection, which was found to be higher than the water-flooding by 8.1, 8.2, 1.7, and $0.8 \%$ for cases $\mathrm{CW}_{0}, \mathrm{CW}_{1}, \mathrm{CW}_{3}$, and $\mathrm{CW}_{5}$, respectively. These results revealed the significance of $\mathrm{CW}$ salinity on RF.

For instance, the final RF was 58 and $60.6 \%$ when the sandstone was flushed with $\mathrm{DI}\left(\mathrm{CW}_{0}\right)$ and $1 \mathrm{wt} \% \mathrm{NaCl}$ $\left(\mathrm{CW}_{1}\right)$ chase water, respectively. On the other hand, with $3 \mathrm{wt}$ $\% \mathrm{NaCl}\left(\mathrm{CW}_{3}\right)$ and 5 wt \% $\mathrm{NaCl}\left(\mathrm{CW}_{5}\right)$ chase water, the ultimate RF was 51 and $46.2 \%$, respectively. The results lead to a thought that there is a direct relationship between chase water salinity and RF.

The recorded pressure drop along the core is shown in Figure 6.

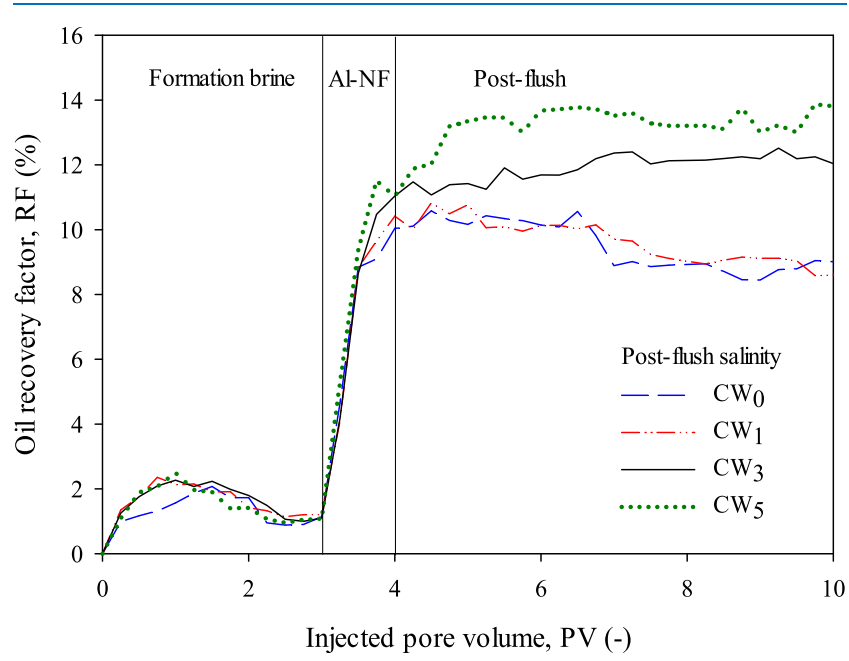

Figure 6. Influence of chase water salinity on the pressure difference.

During FB injection (0-3 PV), the pressure drop along the core increased to $2 \mathrm{MPa}$ and later decreased to $1.5 \mathrm{MPa}$. The decrease in pressure drop is an indication of poor sweeping efficiency of FB. Upon the injection of Al-NF for $0.5 \mathrm{PV}$, the pressure drop increased significantly to $8.6 \mathrm{MPa}$. The results are consistent with the literature, ${ }^{34}$ where the added nano- particles increase the viscosity of the injecting fluid, ${ }^{35,36}$ so the reduced injectivity leads to the increase in pressure drop.

A distinct response of pressure drop to postflush salinity was further observed. In the low-salinity scenario $\left(\mathrm{CW}_{0}\right.$ and $\left.\mathrm{CW}_{1}\right)$, the pressure drop peaked at around $10 \mathrm{MPa}$ and later dropped to $8.5 \mathrm{MPa}$ after injecting $2 \mathrm{PV}$. However, by increasing the salt concentration $\left(\mathrm{CW}_{3}\right.$ and $\left.\mathrm{CW}_{5}\right)$, the pressure drop increases up to 11 and $13 \mathrm{MPa}$, respectively. The pressure drop response in a low-salinity medium is plausibly due to the wettability alteration where Al-NPs are attached to the pore surfaces through the mechanism of the structural disjoining pressure.

With the pressure drop decreasing to $8.5 \mathrm{MPa}$, the results suggested that Al-NPs are adsorbed onto the pore surface wall during EOR, which was also reported by $\mathrm{Li}$ et al. ${ }^{37}$ On the other hand, upon flushing the sandstone with a highly saline water $\left(\mathrm{CW}_{3}\right.$ and $\left.\mathrm{CW}_{5}\right)$, it is likely that heteroaggregation of $\mathrm{Al}$ NPs is the primary reason for the pressure drop response. As Al-NF travels within the core, SDBS is gradually decreased by adsorption onto the rock surface. The tolerance of Al-NF stability to the higher $\mathrm{NaCl}$ concentration is weakened at a lower concentration of SDBS (base fluid). This mechanism is explained in Figure 12 by monitoring the SDBS concentration within the effluent water. Although unfavorable for this study, the literature reports that the heteroaggregation of Al-NPs could be beneficial for a pore blocking agent study in heterogeneous reservoirs. ${ }^{38}$

3.2.2. Formation Damage. To shed light on the effects of salinity of chase water on RF and pressure drop along the core during the core-flood test, the core surface was investigated at the end of the experiment. SEM images of the core inlet are shown in Figure 7.

Chasing with $\mathrm{CW}_{0}$ and $\mathrm{CW}_{1}$ at the trail of the $\mathrm{Al}-\mathrm{NF}$ slug shows a clean surface with some traces of Al-NPs (as per circles in Figure 7a,b) adsorbed onto the rock surface. Based on the surface observation, there is no agglomeration of $\mathrm{Al}$ NPs observed at the inlet. On the other hand, there is significant precipitation upon chasing with $\mathrm{CW}_{3}$ and $\mathrm{CW}_{5}$. The precipitation is strongly believed to be formed by nanoparticle aggregation.

SEM images are consistent with the pressure-drop observation for $\mathrm{CW}_{0}$ and $\mathrm{CW}_{1}$ (Figure 6). Based on Figure $7 \mathrm{a}, \mathrm{b}$, the decrease in pressure drop could be associated with the desorption of Al-NPs. $\mathrm{CW}_{3}$ and $\mathrm{CW}_{5}$ (Figure $7 \mathrm{c}, \mathrm{d}$ ) indicate that high-salinity chase water degrades Al-NF. In addition to the core surface observation, quantitative elemental analysis of the observation spots was performed by energy-dispersive Xray spectroscopy (EDX) to determine the composition of the pore blocking agents.

The results are shown in Figure 8.

The results showed that sodium $(\mathrm{Na})$ and chlorine $(\mathrm{Cl})$ are absent from the core surface in the cases of $\mathrm{CW}_{0}$ and $\mathrm{CW}_{1}$. It is in line with the concentration of aluminum ( $\mathrm{Al})$, that is, 1 and 3 wt \%, respectively. A clear contrast is found in the cases of $\mathrm{CW}_{3}$ and $\mathrm{CW}_{5}$ where $\mathrm{Al}$ is attached to the core surface at 15.3 and $14.9 \mathrm{wt} \%$, respectively. The observed $\mathrm{Al}$ is the main component of the primary nanoparticles $\left(\mathrm{Al}_{2} \mathrm{O}_{3}\right)$ used in this study.

A high concentration of $\mathrm{Na}$ and $\mathrm{Cl}$ is the main agent that promotes the agglomeration of nanoparticles, hence leading to their precipitation. The precipitates of nanoparticles and salt then cover the quartz minerals $\left(\mathrm{SiO}_{2}\right)$ of the rock surface. As a 


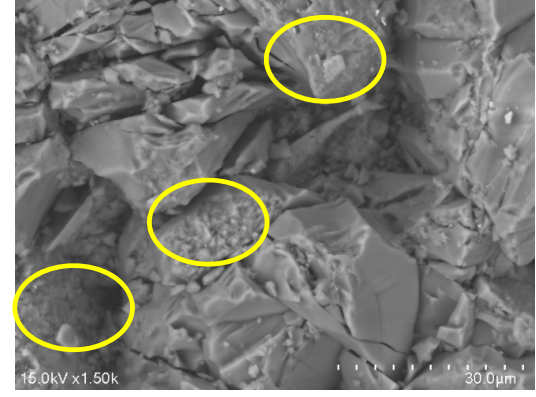

(a) $\mathrm{CW}_{0}$

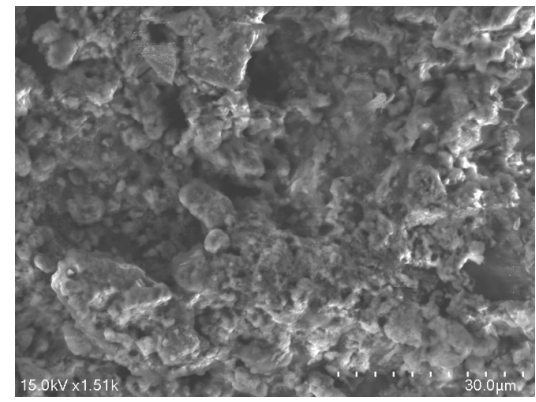

(c) $\mathrm{CW}_{3}$

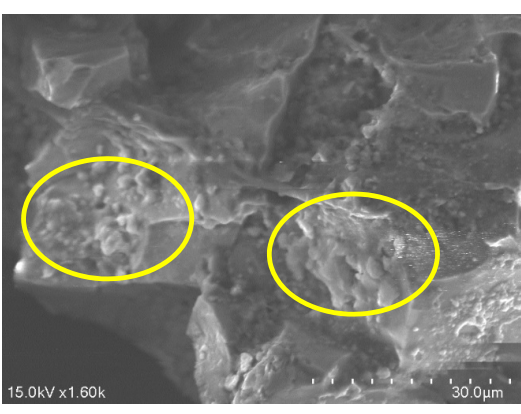

(b) $\mathrm{CW}_{1}$

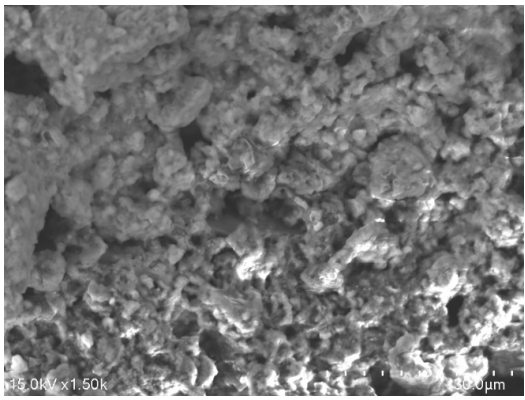

(d) $\mathrm{CW}_{5}$

Figure 7. Core surface after the core-flooding experiment: (a) DI water as postflush $\mathrm{CW}_{0}$, (b) $1 \mathrm{wt} \% \mathrm{NaCl}$ water as postflush $\mathrm{CW}_{1}$, (c) $3 \mathrm{wt} \%$ $\mathrm{NaCl}$ as postflush $\mathrm{CW}_{3}$, and (d) 5 wt $\% \mathrm{NaCl}$ as postflush $\mathrm{CW}_{5}$.

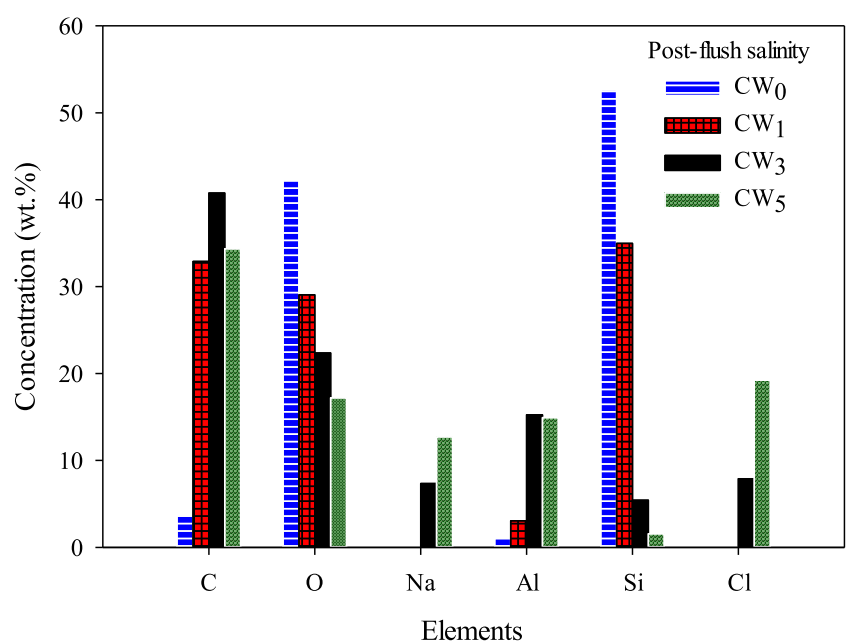

Figure 8. Elemental composition of the core surface at post coreflooding using various salinities of chase water.

result, silicon $(\mathrm{Si})$ and oxygen $(\mathrm{O})$ show a reverse relationship with the increasing salinity gradient (from 0 to $5 \mathrm{wt} \% \mathrm{NaCl}$ ).

3.3. Chemistry of the Effluent Water. Effluent in the producing fractionator was collected throughout the coreflooding tests. The nanoparticles within the effluent were monitored, and the results are shown in Figure 9.

Al-NPs were found to adsorb within porous media of the core. At the breakthrough, up to $70 \%$ of nanoparticles adsorbed onto the core, as evidenced by the low concentration in the effluent water. In the case of $\mathrm{CW}_{3}$ and $\mathrm{CW}_{5}$, the adsorption increases to 91 and 97\%, respectively. The nanoparticles decrease gradually upon continous injection of chase water. This is believed to be due to a dilution effect caused by the chase water. A material balance is then further performed to compute the total Al-NPs adsorbed.

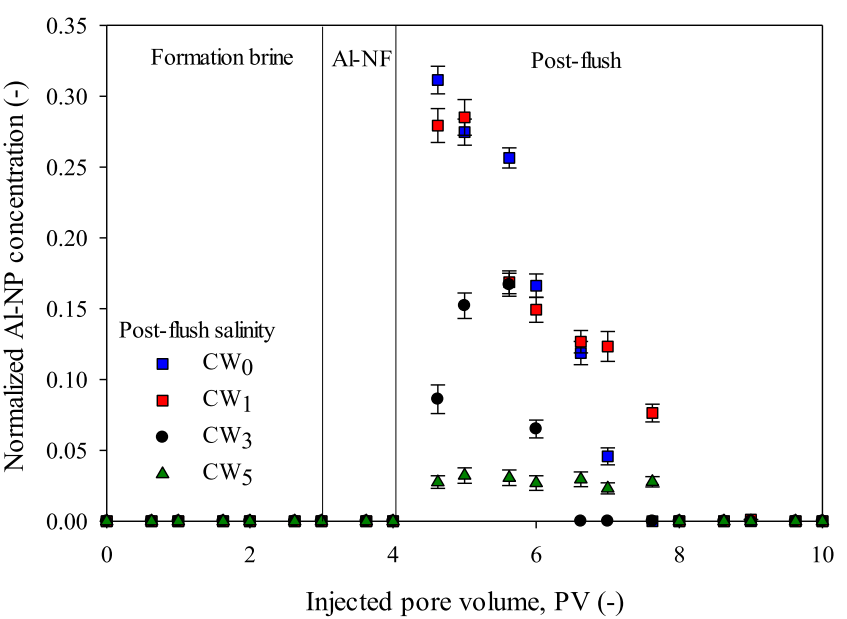

Figure 9. Nanoparticle tracking in the effluent during core-flooding.

It was found that 24.9 and $24.6 \mathrm{mg}$ of total $64 \mathrm{mg}$ of injected nanoparticles were adsorbed in the cases of $\mathrm{CW}_{0}$ and $\mathrm{CW}_{1}$, respectively, which means approximately $40 \%$. The injected nanoparticles were found to be significantly depleted upon driving with $\mathrm{CW}_{3}$ and $\mathrm{CW}_{5}$, where 48.7 and $57.4 \mathrm{mg}$ of nanoparticles failed to remain in the effluent, and this added up to 76.1 and $90 \%$ nanoparticles trapped within the core, respectively.

These observations contradict to those presented by Kiani et al., ${ }^{15}$ who did not observe any formation damage. In our work, the pore blockage observed at the inlet restrains the injected Al-NPs from flowing toward the producing end, thereby failing to alter the wettability. Therefore, the greater the Al-NP loss, the lower the RF. From $\mathrm{Na}^{+}$ion tracking, further insights could be drawn. The results are shown in Figure 10. 


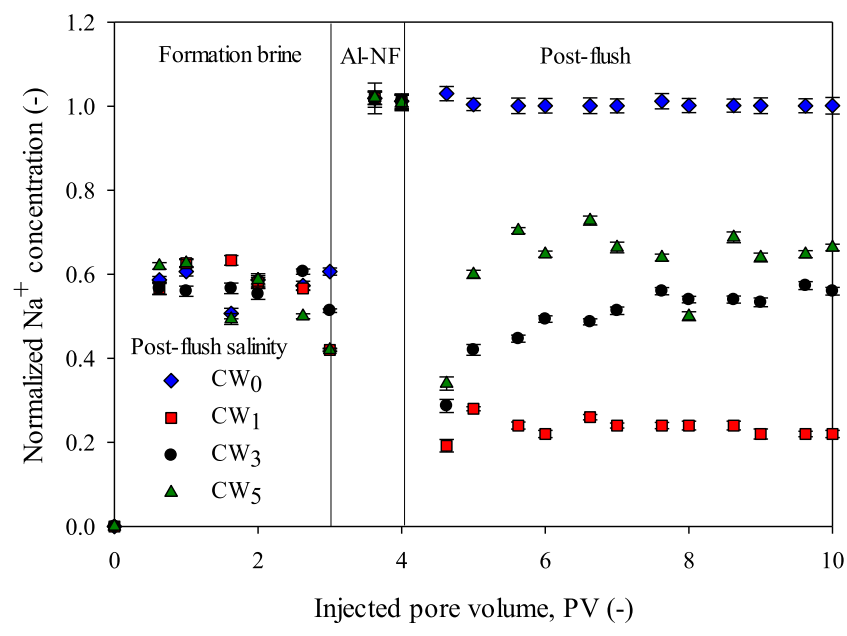

Figure 10. $\mathrm{Na}^{+}$tracking in the effluent during core-flooding.

It was observed that when the chase water contains $\mathrm{Na}^{+}$ions $\left(\mathrm{CW}_{1}, \mathrm{CW}_{3}\right.$, and $\left.\mathrm{CW}_{5}\right)$, it is adsorbed within the core (during postflush). On the contrary, injecting $\mathrm{CW}_{0}$ leads to $\mathrm{Na}^{+}$ desorption. This is believed to be caused by the dissolved salt content that was previously adsorbed during FB injection. Also, one could observe that the ratio of trapped $\mathrm{Na}^{+}$increased following the sequence $\mathrm{CW}_{1}>\mathrm{CW}_{3}>\mathrm{CW}_{5}$. As per Figure 10, the loss of $\mathrm{Na}^{+}$in the $\mathrm{CW}_{3}$ and $\mathrm{CW}_{5}$ cases is clearly explained by pore blocking induced by Al-NP adsorption (Figure 8 ). The adsorbed $\mathrm{Al}-\mathrm{NPs}$ at the inlet narrowed the flowing path of the chase water, so that a portion of injected $\mathrm{Na}^{+}$was unable to travel to the producing end.

However, for the scenario in which $\mathrm{CW}_{1}$ was used, the precipitation of Al-NPs was not significant, which led to the rationale that $\mathrm{Na}^{+}$loss during chase water-flooding should be related to the adsorption displacement of Al-NPs. The adsorption and desorption of nanoparticles are defined as the dynamic balance process controlled by the forces between nanoparticles and pore walls. ${ }^{39}$ These forces are expressed by the van der Waals attractive force and the repulsive force of the electrical double layer.

In explaining the production mechanisms during low-salinity water-flooding (LSWF), Chavan et al. ${ }^{40}$ argued that multicomponent ion exchange (MIE) plays a key role. MIE first expands and opens up the outer diffuse layer, and then monovalent ions within the injecting phase replace the divalent ions of the adsorption layer. As a result, divalent ions are released and produced from the reservoir.

Extending this analysis to this study, we think that the adsorption of $\mathrm{Na}^{+}$in the core by $\mathrm{CW}_{1}$ is caused by an adsorption substitution with nanoparticles following MIE of the LSWF approach. Thus, $\mathrm{Ca}^{2+}$ ions were tracked to assert this point. The results are shown in Figure 11.

The results, herein conveyed, confirmed the displacement mechanism of MIE. Injecting $\mathrm{CW}_{1}$ mitigates the heteroaggregation of Al-NF. Thus, the wettability alteration is therefore achieved by nanoparticle adsorption. MIE is believed to occur at the contact layer of the nanoparticle film rather than the pore surface. However, injecting $\mathrm{CW}_{3}$ and $\mathrm{CW}_{5}$ prompts either homoaggregation or heteroaggregation of the Al-NPs. This causes the formation of aggregates at the inlet (Figure 7).

As a result, chase water of these cases interacts directly with the pore surface when flowing to the producing end, so that

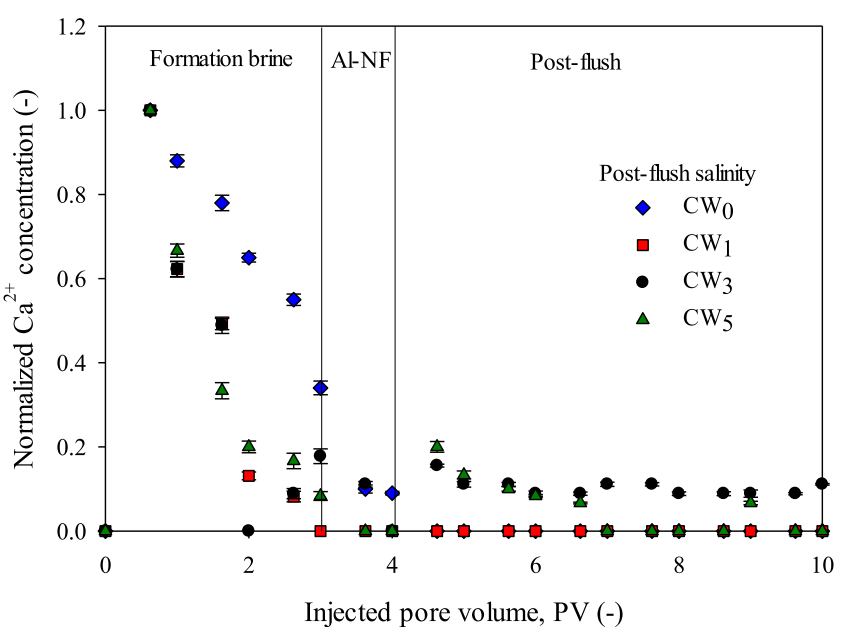

Figure 11. $\mathrm{Ca}^{2+}$ tracking in the effluent during core-flooding.

$\mathrm{Ca}^{2+}$ is released and it travels to the effluent. The same observation was found in every case during FB injection where $\mathrm{Ca}^{2+}$ is released by the interaction between the pore surface and the injecting brine. As SDBS is used as a stabilizing agent for nanoparticles, monitoring the SDBS concentration in the effluent provides a better insight into how alumina nanoparticles are destabilized. The results are shown in Figure 12.

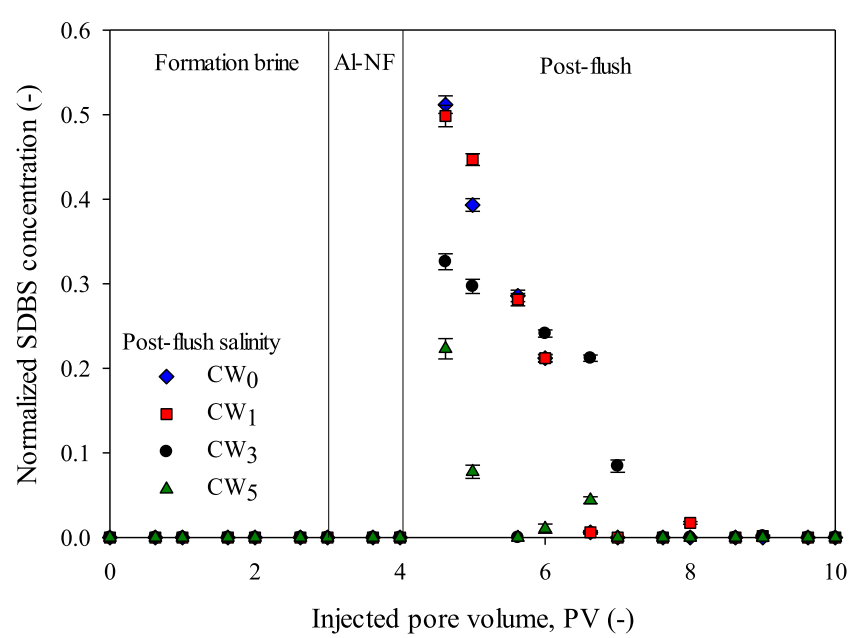

Figure 12. SDBS monitoring during core-flooding.

As aqueous SDBS is used as the base fluid, its concentration is therefore vital because higher concentration of SDBS monomers possesses repulsive force that prevents alumina nanoparticles from forming aggregates. ${ }^{25}$ Figure 12 indicates that after the SDBS breakthrough, the SDBS concentration drops drastically in the case of $\mathrm{CW}_{5}$. On the other hand, chasing with $\mathrm{CW}_{0}, \mathrm{CW}_{1}$, and $\mathrm{CW}_{3}$ was found to have a similar trend.

However, the computed percentage of recovered SDBS was 65.1, 75, 59.2, and $20 \%$ for $\mathrm{CW}_{0}, \mathrm{CW}_{1}, \mathrm{CW}_{3}$, and $\mathrm{CW}_{5}$, respectively. Despite the dedicated repulsive forces, a high concentration of SDBS leads to better tolerance to the highsalinity environment. Therefore, the lower the SDBS concentration, the greater the propensity of Al-NPs to aggregate and later deposit, which is consistent with the literature. $^{41}$ 


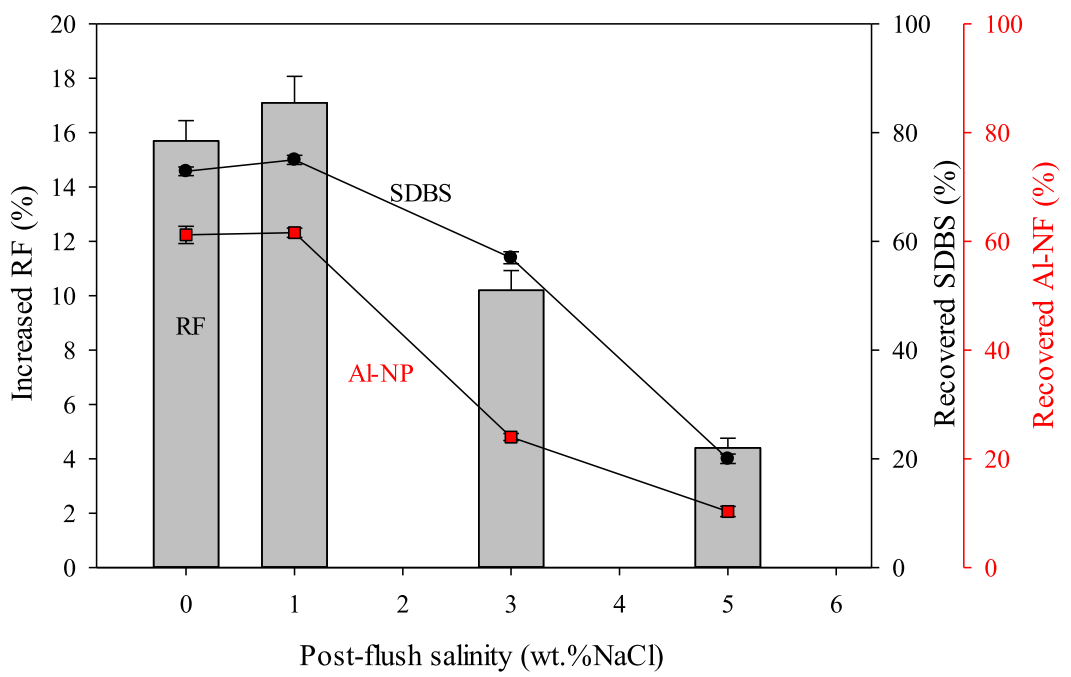

Figure 13. Relationship of the increased oil recovery with recovered SDBS and alumina nanoparticles.

A relationship can be established between the results of RF, recovered SDBS, and Al-NPs (Figure 13). It could be seen that the SDBS concentration has a negative correlation with the stability of Al-NPs.

With increasing destabilized Al-NPs, the deposition clogs the flow path of both displacing and displaced phases, thereby reducing the RF as well. These effects are mitigated by injecting lower salinity $\mathrm{CW}_{1}$ where the pressure could be lowered by $35 \%$, even though up to $40 \%$ of nanoparticles are trapped within the core.

\section{CONCLUSIONS}

Formation damage during an enhanced oil recovery (EOR) process involving the injection of alumina nanofluid (Al-NF) slug after water-flooding in a low-permeability sandstone was studied. The key findings are summarized as follows:

(1) The formulated Al-NF by SDBS was found to reduce IFT from 23.1 to $4.5 \mathrm{mN} / \mathrm{m}$ and contact angle from 166 to $50^{\circ}$ (strongly water-wet conditions).

(2) Injection of Al-NF was found to enhance oil recovery up to $17.2 \%$ over water-flooding.

(3) Injecting a high-salinity chase water (3 wt \% $\mathrm{NaCl}$ ) reduces the oil recovery factor to $8.7 \%$ from $17.2 \%$ owing to heteroaggregation of Al-NPs.

(4) The deposited nanoparticles at the core inlet caused up to $13 \mathrm{MPa}$ pressure drop due to the clog in the lowpermeability core, which later resulted in the formation damage.

(5) The heteroaggregation of Al-NPs is due to a dilution of the base fluid after interaction with the reservoir rock and in situ fluids (oil and water) within.

(6) Reducing the salinity of chase water to lower than $1 \mathrm{wt}$ $\% \mathrm{NaCl}$ mitigated the formation damage by decreasing the trapped nanoparticles to $40 \%$ and causing a pressure drop of up to $35 \%$.

This study has demonstrated that high-salinity postflush catalyzes the formation damage. Low-salinity water was employed and MIE of the LSWF approach was followed to mitigate the damage. However, the mitigation has yet pronounced due to the scope and core of the topic. Some improvements could be made in the future study such as developing the postflush carrying certain salt ions that are able to further desorb the trapped nanoparticles or investigating additives that prevent the adsorption of nanoparticles during the injection.

\section{ASSOCIATED CONTENT}

\section{Supporting Information}

The Supporting Information is available free of charge at https://pubs.acs.org/doi/10.1021/acsomega.0c02473.

Determination of the Al-NP concentration; on behalf of all authors, I would like to confirm that photos in Figure $\mathrm{S} 1$ were taken by the corresponding author of this article (PDF)

\section{AUTHOR INFORMATION}

\section{Corresponding Author}

Ichhuy Ngo - Resources Production and Safety Engineering Laboratory, Department of Earth Resources Engineering, Kyushu University, Fukuoka 819-0395, Japan; Energy Technology and Management Unit, Research and Innovation Center, Institute of Technology of Cambodia, Phnom Penh, Cambodia; 10 orcid.org/0000-0002-6029-1239;

Email: ngoichhuy2011@gmail.com

\section{Authors}

Kyuro Sasaki - Resources Production and Safety Engineering Laboratory, Department of Earth Resources Engineering, Kyushu University, Fukuoka 819-0395, Japan

Ronald Nguele - Resources Production and Safety Engineering Laboratory, Department of Earth Resources Engineering, Kyushu University, Fukuoka 819-0395, Japan; 이이. org/ 0000-0002-0364-0017

Yuichi Sugai - Resources Production and Safety Engineering Laboratory, Department of Earth Resources Engineering, Kyushu University, Fukuoka 819-0395, Japan

Complete contact information is available at: https://pubs.acs.org/10.1021/acsomega.0c02473

\section{Notes}

The authors declare no competing financial interest. 


\section{ACKNOWLEDGMENTS}

The authors would like to express their gratitude to the Japan Petroleum Exploration Company (JAPEX) for supplying the crude oil sample and AUN/SEED-Net for financial support.

\section{REFERENCES}

(1) Alvarado, V.; Manrique, E. Enhanced Oil Recovery: An Update Review. Energies 2010, 3, 1529-1575.

(2) Muggeridge, A.; Cockin, A.; Webb, K.; Frampton, H.; Collins, I.; Moulds, T.; Salino, P. Recovery Rates, Enhanced Oil Recovery and Technological Limits. Philos. Trans. R. Soc., A 2014, 372, No. 20120320.

(3) Khajehpour, M.; Etminan, S. R.; Goldman, J.; Wassmuth, F.; Bryant, S. Nanoparticles as Foam Stabilizer for Steam-Foam Process. SPE J. 2018, 23, 2232-2242.

(4) Giraldo, J.; Benjumea, P.; Lopera, S.; Corte's, F. B.; Ruiz, M. A. Wettability Alteration of Sandstone Cores by Alumina-Based Nanofluids. Energy Fuels 2013, 27, 3659-3665.

(5) Arab, D.; Kantzas, A.; Bryant, S. L. In Nanoparticle-Enhanced Surfactant Floods to Unlock Heavy Oil, SPE Improved Oil Recovery Conference; Society of Petroleum Engineers, 2018.

(6) Sadeghzadeh, M.; Maddah, H.; Ahmadi, M. H.; Khadang, A.; Ghazvini, M.; Mosavi, A.; Nabipour, N. Prediction of ThermoPhysical Properties of TiO2-Al2O3/Water Nanoparticles by Using Artificial Neural Network. Nanomaterials 2020, 10, No. 697.

(7) Baghban, A.; Sasanipour, J.; Pourfayaz, F.; Ahmadi, M. H.; Kasaeian, A.; Chamkha, A. J.; Oztop, H. F.; Chau, K. Towards Experimental and Modeling Study of Heat Transfer Performance of Water- $\mathrm{SiO} 2$ Nanofluid in Quadrangular Cross-Section Channels. Eng. Appl. Comput. Fluid Mech. 2019, 13, 453-469.

(8) Ramezanizadeh, M.; Alhuyi Nazari, M.; Ahmadi, M. H.; Chau, K. Experimental and Numerical Analysis of a Nanofluidic Thermosyphon Heat Exchanger. Eng. Appl. Comput. Fluid Mech. 2019, 13, 4047.

(9) Razavi, R.; Sabaghmoghadam, A.; Bemani, A.; Baghban, A.; Chau, K.; Salwana, E. Application of ANFIS and LSSVM Strategies for Estimating Thermal Conductivity Enhancement of Metal and Metal Oxide Based Nanofluids. Eng. Appl. Comput. Fluid Mech. 2019, $13,560-578$.

(10) Onyekonwu, M. O.; Ogolo, N. A. In Investigating the Use of Nanoparticles in Enhancing Oil Recovery, Nigeria Annual International Conference and Exhibition; Society of Petroleum Engineers, 2010.

(11) Hendraningrat, L.; Shidong, L.; Torsaeter, O. In A Glass Micromodel Experimental Study of Hydrophilic Nanoparticles Retention for EOR Project, SPE Russian Oil and Gas Exploration and Production Technical Conference and Exhibition; Society of Petroleum Engineers, 2012.

(12) Shahrabadi, A.; Bagherzadeh, H.; Roostaie, A.; Golghanddashti, H. In Experimental Investigation of Hlp Nanofluid Potential to Enhance Oil Recovery: A Mechanistic Approach, SPE International Oilfield Nanotechnology Conference and Exhibition; Society of Petroleum Engineers, 2012.

(13) Keykhosravi, A.; Simjoo, M. Insights into Stability of Silica Nanofluids in Brine Solution Coupled with Rock Wettability Alteration: An Enhanced Oil Recovery Study in Oil-Wet Carbonates. Colloids Surf., A 2019, 583, No. 124008.

(14) Joonaki, E.; Ghanaatian, S. The Application of Nanofluids for Enhanced Oil Recovery: Effects on Interfacial Tension and Coreflooding Process. Pet. Sci. Technol. 2014, 32, 2599-2607.

(15) Kiani, S.; Mansouri Zadeh, M.; Khodabakhshi, S.; Rashidi, A.; Moghadasi, J. Newly Prepared Nano Gamma Alumina and Its Application in Enhanced Oil Recovery: An Approach to Low-Salinity Waterflooding. Energy Fuels 2016, 30, 3791-3797.

(16) Hosseini, E.; Hajivand, F.; Yaghodous, A.; Soltani, R. Experimental Investigation of the Effect of Dispersed Silica and Alumina Nanoparticles on Oil-Aqueous Phase Interfacial Tension. Pet. Sci. Technol. 2019, 37, 1485-1494.
(17) Li, S.; Torsaeter, O. In The Impact of Nanoparticles Adsorption and Transport on Wettability Alteration of Intermediate Wet Berea Sandstone, SPE Middle East Unconventional Resources Conference and Exhibition; Society of Petroleum Engineers: Muscat, Oman, 2015; p 14.

(18) Sagala, F.; Hethnawi, A.; Nassar, N. N. Hydroxyl-Functionalized Silicate-Based Nanofluids for Enhanced Oil Recovery. Fuel 2020, 269, No. 117462.

(19) Zhang, T.; Murphy, M. J.; Yu, H.; Bagaria, H. G.; Yoon, K. Y.; Nielson, B. M.; Bielawski, C. W.; Johnston, K. P.; Huh, C.; Bryant, S. L. Investigation of Nanoparticle Adsorption during Transport in Porous Media. SPE J. 2015, 20, 667-677.

(20) Sidik, N. A. C.; Mohammed, H. A.; Alawi, O. A.; Samion, S. A Review on Preparation Methods and Challenges of Nanofluids. Int. Commun. Heat Mass Transfer 2014, 54, 115-125.

(21) Nguele, R.; Sreu, T.; Inoue, H.; Sugai, Y.; Sasaki, K. Enhancing Oil Production Using Silica-Based Nanofluids: Preparation, Stability, and Displacement Mechanisms. Ind. Eng. Chem. Res. 2019, 58, 15045-15060.

(22) Orodu, O. D.; Orodu, K. B.; Afolabi, R. O.; Dafe, E. A. Dataset on Experimental Investigation of Gum Arabic Coated Alumina Nanoparticles for Enhanced Recovery of Nigerian Medium Crude Oil. Data Brief 2018, 19, 475-480.

(23) Ngo, I.; Srisuriyachai, F.; Sugai, Y.; Sasaki, K. In Study of Heterogeneous Reservoir Effects on Surfactant Flooding in Consideration of Surfactant Adsorption Reversibility, 23rd Formation Evaluation Symposium of Japan 2017, 2017.

(24) Belhaj, A. F.; Elraies, K. A.; Mahmood, S. M.; Zulkifli, N. N.; Akbari, S.; Hussien, O. S. The Effect of Surfactant Concentration, Salinity, Temperature, and $\mathrm{PH}$ on Surfactant Adsorption for Chemical Enhanced Oil Recovery: A Review. J. Pet. Explor. Prod. Technol. 2020, 10, 125-137.

(25) Yu, F.; Chen, Y.; Liang, X.; Xu, J.; Lee, C.; Liang, Q.; Tao, P.; Deng, T. Dispersion Stability of Thermal Nanofluids. Prog. Nat. Sci.: Mater. Int. 2017, 27, 531-542.

(26) Popa, I.; Gillies, G.; Papastavrou, G.; Borkovec, M. Attractive and Repulsive Electrostatic Forces between Positively Charged Latex Particles in the Presence of Anionic Linear Polyelectrolytes. J. Phys. Chem. B 2010, 114, 3170-3177.

(27) Missana, T.; Adell, A. On the Applicability of DLVO Theory to the Prediction of Clay Colloids Stability. J. Colloid Interface Sci. 2000, 230, 150-156.

(28) Lashkarbolooki, M.; Ayatollahi, S.; Riazi, M. The Impacts of Aqueous Ions on Interfacial Tension and Wettability of an Asphaltenic-Acidic Crude Oil Reservoir during Smart Water Injection. J. Chem. Eng. Data 2014, 59, 3624-3634.

(29) Rosen, M. J.; Kunjappu, J. T. Surfactants and Interfacial Phenomena; A Wiley-Interscience Publication; Wiley, 2012.

(30) Chilingar, G. V.; Yen, T. F. Some Notes on Wettability and Relative Permeabilities of Carbonate Reservoir Rocks, II. Energy Sources 1983, 7, 67-75.

(31) Treiber, L. E.; Owens, W. A Laboratory Evaluation of the Wettability of Fifty Oil-Producing Reservoirs. Soc. Pet. Eng. J. 1972, $12,531-540$.

(32) Wasan, D. T.; Nikolov, A. D. Spreading of Nanofluids on Solids. Nature 2003, 423, 156-159.

(33) Dai, C.; Wang, X.; Li, Y.; Lv, W.; Zou, C.; Gao, M.; Zhao, M. Spontaneous Imbibition Investigation of Self-Dispersing Silica Nanofluids for Enhanced Oil Recovery in Low-Permeability Cores. Energy Fuels 2017, 31, 2663-2668.

(34) Sharma, T.; Iglauer, S.; Sangwai, J. S. Silica Nanofluids in an Oilfield Polymer Polyacrylamide: Interfacial Properties, Wettability Alteration, and Applications for Chemical Enhanced Oil Recovery. Ind. Eng. Chem. Res. 2016, 55, 12387-12397.

(35) Baghban, A.; Jalali, A.; Shafiee, M.; Ahmadi, M. H.; Chau, K. Developing an ANFIS-Based Swarm Concept Model for Estimating the Relative Viscosity of Nanofluids. Eng. Appl. Comput. Fluid Mech. 2019, 13, 26-39. 
(36) Ahmadi, M. H.; Mohseni-Gharyehsafa, B.; Farzaneh-Gord, M.; Jilte, R. D.; Kumar, R.; Chau, K. Applicability of Connectionist Methods to Predict Dynamic Viscosity of Silver/Water Nanofluid by Using ANN-MLP, MARS and MPR Algorithms. Eng. Appl. Comput. Fluid Mech. 2019, 13, 220-228.

(37) Li, K.; Wang, D.; Jiang, S. Review on Enhanced Oil Recovery by Nanofluids. Oil Gas Sci. Technol. d'IFP Energies Nouv. 2018, 73, 37.

(38) Shi, S.; Wang, Y.; Li, Z.; Chen, Q.; Zhao, Z. Laboratory Investigation of the Factors Impact on Bubble Size, Pore Blocking and Enhanced Oil Recovery with Aqueous Colloidal Gas Aphron. J. Pet. Explor. Prod. Technol. 2016, 6, 409-417.

(39) Bedeaux, D.; Flekkøy, E. G.; Hansen, A.; Kjelstrup, S.; Måløy, K. J.; Torsaeter, O. Physics of Porous Media. In Frontiers Research Topics; Frontiers Media: SA, 2020.

(40) Chavan, M.; Dandekar, A.; Patil, S.; Khataniar, S. Low-SalinityBased Enhanced Oil Recovery Literature Review and Associated Screening Criteria. Pet. Sci. 2019, 16, 1344-1360.

(41) Al-Waeli, A. H. A.; Chaichan, M. T.; Kazem, H. A.; Sopian, K. Evaluation and Analysis of Nanofluid and Surfactant Impact on Photovoltaic-Thermal Systems. Case Stud. Therm. Eng. 2019, 13, No. 100392 